\title{
Dystrophin Dp71 Is Critical for the Clustered Localization of Potassium Channels in Retinal Glial Cells
}

\author{
Nathan C. Connors and Paulo Kofuji \\ Department of Neuroscience, University of Minnesota, Minneapolis, Minnesota 55455
}

The Müller cell is the principal glial cell of the vertebrate retina. The primary conductance in Müller cells is the inwardly rectifying potassium channel Kir4.1 (BIR10 and KAB-2), which is highly concentrated at the endfeet at the vitreal border and to processes enveloping blood vessels. Such asymmetric and clustered distribution of Kir4.1 channels in Müller cells is thought to be critical for the buffering of extracellular potassium concentration in retina. Herein we investigated whether the distribution and functional properties of Kir4.1 channels are dependent on expression of the Dp71, a dystrophin isoform expressed in Müller cells. Kir4.1 distribution was determined in mouse retinal sections and whole mounts using anti-Kir4.1 antibodies and confocal microscopy. In Müller cells from wildtype mice, Kir4.1 is highly clustered in their endfeet and perivascular processes. In contrast, in Müller cells from the

Discrete and clustered localization of ion channels and receptors are critical for the signaling properties of neurons. Channels and receptors are often localized in specific neuronal compartments within axons, dendrites, or the cell body (Sheng and Kim, 1996; Sheng and Wyszynsky, 1997). In glial cells, clustered localization of channels and receptors has also been demonstrated (Newman, 1985, 1987). Inwardly rectifying potassium (Kir) channels are highly concentrated in the endfoot of retinal glial Müller cell and sparsely expressed in other domains of the cell (Newman, 1993). Such asymmetric and highly clustered localization of Kir channels subserves an important physiological function: $\mathrm{K}^{+}$released from active neurons in the inner retina is shunted to the vitreous compartment, preventing large changes in extracellular potassium concentration $\left(\left[\mathrm{K}^{+}\right]_{\mathrm{o}}\right)$ (Newman et al., 1984). Such buffering of $\left[\mathrm{K}^{+}\right]_{\mathrm{o}}$ in retina by the directed flux of $\mathrm{K}^{+}$through the Müller cells is known as potassium siphoning (Newman et al., 1984). Despite its importance, the molecular mechanism by which the Kir channels are targeted and clustered in Müller cells remains unknown.

The inwardly rectifying potassium channel Kir4.1 is the primary $\mathrm{K}^{+}$conductance of the Müller cell (Kof uji et al., 2000) and has a subcellular distribution pattern expected for the potassium siphoning function (Ishii et al., 1997; Nagelhus et al., 1999; Kof uji

\footnotetext{
Received Jan. 11, 2002; revised April 1, 2002; accepted April 3, 2002.

This work was supported by National Institutes of Health Grant EY12949-01 to P.K. and Vision Training Grant EY07133 to N.C.C. We are very grateful to Dr. E. Newman for critical evaluation of earlier drafts of this manuscript, Terry Wu for his assistance on the use of the confocal microscope, and Paul Ceelen for the Müller cell figure.

Correspondence should be addressed to Paulo Kofuji, Department of Neuroscience, 6-145 Jackson Hall, 321 Church Street SE, Minneapolis, MN 55455. E-mail: kofuj001@tc.umn.edu.

Copyright (ㄷ) 2002 Society for Neuroscience $\quad 0270-6474 / 02 / 224321-07 \$ 15.00 / 0$
}

$m d x^{3 C v}$ mouse, which lacks the expression of Dp71, the Kir4.1 immunoreactivity is evenly distributed throughout the cell membrane. Surface expression of Kir4.1 is not affected in $\mathrm{mdx}^{3 \mathrm{Cv}}$ Müller cells as current density of barium-sensitive inward currents in $\mathrm{mdx}^{3 \mathrm{C} v}$ Müller cells are not different from wild type. Focal extracellular potassium increases in isolated Müller cells shows that Kir channels in the $\mathrm{mdx}^{3 \mathrm{C} v}$ cells, as opposed to wild type, are less prominently concentrated in their endfeet. In summary, our data indicate that Dp71 is critical for the clustering but not membrane expression of Kir4.1 in mouse Müller cells. These results point to a new role for dystrophin in glial cells.

Key words: Kir4.1; Müller cells; retina; potassium siphoning; immunolocalization; inward-rectifying potassium channel

et al., 2000). Recently, immunoelectron microscopy studies demonstrated that the water channel aquaporin-4 (AQP4) is tightly colocalized with Kir4.1 in Müller cells (Nagelhus et al., 1999), suggesting a shared molecular mechanism for subcellular localization. Sequence analysis of Kir4.1 and AQP4 channels reveals that they each contain a C-terminal consensus sequence for binding to PDZ [postsynaptic density-95 (PSD)/Discs large/zona occludens-1] domain-containing proteins. PDZ domains are $\sim 90$ amino acids in length and have been found to bind the $\mathrm{C}$ terminus of many channels, including $\mathrm{Kv}$ channels and NMDA receptors (Sheng and Wyszynsky, 1997).

A candidate interacting protein for involvement in the localization of Kir4.1 and AQP4 in Müller cells is the PDZ domaincontaining $\alpha 1$-syntrophin, which subsists in Müller cells as part of the dystrophin-associated protein complex (DAPC) (Claudepierre et al., 2000). The DAPC is a multiprotein complex that spans the cell membrane to bridge the extracellular matrix with the actin cytoskeleton. Both $\alpha 1$-syntrophin and PSD-93, which was also suggested to be associated with the Müller cell DAPC (Claudepierre et al., 2000), contain PDZ domains, providing a possible link to Kir4.1. Additional evidence for the role of the DAPC in the localization of Kir4.1 is the fact that the subcellular distribution pattern of the dystrophin isoform Dp71, the core protein of the Müller-specific DAPC, is strikingly similar to Kir4.1 (Howard et al., 1998).

Based on the above body of evidence, we hypothesized that the DAPC, specifically Dp71, is critical for the localization of Kir4.1 in Müller cells. We used $\mathrm{mdx}^{3 C v}$ mice, which is a functional Dp71 knock-out mouse line (Cox et al., 1993), to show that the discrete localization of Kir4.1 but not the overall expression level is disrupted in Müller cells lacking Dp71. 


\section{MATERIALS AND METHODS}

\section{Antibodies}

For immunocytochemistry, we used rabbit anti-Kir4.1 (Alomone Labs, Jerusalem, Israel), monoclonal anti-glutamine synthetase, and guinea pig anti-GLAST (L-glutamate/L-aspartate transporter) (EAAT1) (Chemicon, Temecula, CA). Alexa Fluor goat anti-rabbit 488, Alexa Fluor goat anti-mouse 594, or Alexa Fluor goat anti-guinea pig 594 (Molecular Probes, Eugene, OR) secondary antibodies were used in immunohistochemical analysis. For immunohistochemistry and Western blots, rabbit anti-Kir4.1 generated against the peptide CEKEGSALSVRISNV and characterized previously (Kof uji et al., 2000) was also used. Monoclonal anti-dystrophin (C terminus) (Chemicon) was used for the Western blot in Figure $3 A$.

\section{Immunocytochemistry}

Sections. Adult postnatal day 21 (P21) to P26 wild-type (C57BL/6J) and $\mathrm{mdx}^{3 C v}$ mice (The Jackson Laboratory, Bar Harbor, ME) were deeply anesthetized, and eyes were quickly enucleated and dissected. Eyecups were dissected out and fixed overnight in $4 \%$ paraformaldehyde $-0.1 \mathrm{M}$ phosphate buffer at $4^{\circ} \mathrm{C}$. After several washes in PBS, the eyecups were cryoprotected in $30 \%$ sucrose-PBS solution, cut into $20 \mu \mathrm{m}$ sections, and collected onto poly-lysine coated slides. Sections were blocked for $1 \mathrm{hr}$ in PBS containing $10 \%$ goat serum, $1 \%$ BSA, and $0.5 \%$ Triton X-100. Antibody incubations were conducted in PBS containing 3\% goat serum, $1 \%$ BSA, $0.5 \%$ Triton $\mathrm{X}-100$, and $0.025 \%$ sodium azide. Primary antibody incubation was conducted overnight at $4^{\circ} \mathrm{C}$. Sections were then washed three times for $10 \mathrm{~min}$ each in PBS and then incubated with secondary antibodies for $1 \mathrm{hr}$ at room temperature. Sections were washed two times for $10 \mathrm{~min}$ each in PBS, mounted in Vectashield (Vector Laboratories, Burlingame, CA), and then imaged with a Leica (Wetzlar, Germany) TCS4D confocal microscope, using a $40 \times$ oil immersion lens. Optical sections were collected at $0.90-1.0 \mu \mathrm{m}$ intervals, and reconstructions of several optical images onto a single plane were performed using Metamorph software (Universal Imaging, Downingtown, PA). Images were processed using Adobe Photoshop 5.0.2 (Adobe Systems, San Jose, CA).

Whole-mount tissue. Eyecups of $\mathrm{P} 35$ wild-type and $\mathrm{mdx}^{3 C v}$ mice were dissected out, and scleras were peeled back to reveal isolated retinas. Retinas were fixed overnight in $4 \%$ paraformaldehyde $-0.1 \mathrm{M}$ phosphate solution at $4^{\circ} \mathrm{C}$ and then washed extensively in PBS before blocking for $3 \mathrm{hr}$ at room temperature in PBS containing 10\% goat serum, $1 \%$ BSA, and $0.5 \%$ Triton $\mathrm{X}-100$. Tissues were then incubated for $3-4 \mathrm{~d}$ at $4{ }^{\circ} \mathrm{C}$ in primary antibodies and then washed six times for 20 min each in PBS before incubation in secondary antibodies for $3-4 \mathrm{~d}$ at $4^{\circ} \mathrm{C}$. Retinal issue was then imaged as described above for retinal sections.

\section{Electrophysiological measurements}

Retinas from P29-P38 wild-type (C57BL/6J) or $\mathrm{mdx}^{3 \mathrm{Cv}}$ mice were incubated at $37^{\circ} \mathrm{C}$ for $20-30 \mathrm{~min}$ in Dulbecco's $\mathrm{Ca}^{2+} / \mathrm{Mg}^{2+}$-free solution supplemented with $0.7 \mathrm{mg} / \mathrm{ml}$ papain (Worthington, Lakewood, $\mathrm{NJ}$ ) and $2.5 \mathrm{mM}$ L-cysteine. Retinas were then washed three times in DMEM$10 \%$ fetal bovine serum solution and kept on ice for 10 min in DMEM$10 \%$ fetal bovine serum-0.1 mg/ml DNase I (Sigma, St. Louis, MO). The retinas were then triturated gently with a large-bore, fire-polished Pasteur pipette. The cell suspension was then transferred to the recording chamber. Müller cells were recognized by their characteristic morphology. Whole-cell voltage-clamp recordings (Hamill et al., 1981) were performed with the pipette attached to the cell soma at room temperature using an Axopatch 200B amplifier (Axon Instruments, Union City, CA). Bath solution consisted of (in $\mathrm{mM}$ ): $140 \mathrm{NaCl}, 2.5 \mathrm{KCl}, 3 \mathrm{CaCl}_{2}, 0.5$ $\mathrm{MgCl}_{2}, 15$ dextrose, and 5 HEPES, pH 7.4 with $\mathrm{NaOH}$. For some experiments, a final concentration of $100 \mu \mathrm{M}$ or $1 \mathrm{mM} \mathrm{BaCl}_{2}$ was added to the bath solution. The intracellular solution consisted of (in $\mathrm{mM}$ ): 5 $\mathrm{NaCl}, 120 \mathrm{KCl}, 1 \mathrm{CaCl}_{2}, 7 \mathrm{MgCl}_{2}, 5$ EGTA, 5 HEPES, and $5 \mathrm{NaATP}$, $\mathrm{pH} 7.2$ with $\mathrm{NaOH}$. When filled with intracellular solution, pipette resistances ranged from 2.5 to $5 \mathrm{M} \Omega$. Data was acquired using a Digidata 1200 analog-to-digital converter (Axon Instruments) interfaced with an IBM-compatible computer running Clampex 8.1 software (Axon Instruments). The low-pass filter was set to $5 \mathrm{kHz}$, and series resistance and capacitance compensation were not used during recording. Cells were used up to $6 \mathrm{hr}$ after dissociation. Off-line analysis and data illustration were conducted using Clampfit 8.1 (Axon Instruments) and Sigmaplot (SPSS, Chicago, IL). For potassium ejection experiments, Müller cells were dissociated and voltage clamped as described above. A second pipette was backfilled with high $\mathrm{K}^{+}$solution consisting of (in $\mathrm{mm}$ ): 92.5
$\mathrm{NaCl}, 50 \mathrm{KCl}, 3 \mathrm{CaCl}_{2}, 0.5 \mathrm{MgCl}_{2}, 15$ dextrose, and 5 HEPES, pH 7.4 with $\mathrm{NaOH}$; the pipette was positioned onto selected regions of the cell via a motorized micromanipulator. Computer-triggered ejections of the high $\mathrm{K}^{+}$solution from the tip of the pipette was controlled by a PV820 pneumatic picopump (World Precision Instruments, Sarasota, FL) set at $\sim 7.5 \mathrm{psi}$ and connected to the pipette holder by plastic tubing. Duration of the ejections was set at $10 \mathrm{msec}$, and current recordings were performed with the cells held at $-80 \mathrm{mV}$. Data was recorded and analyzed as described above.

\section{Western blots}

Whole brain and retinas were dissected from P30 mice and homogenized using an ice-cold solution consisting of $320 \mathrm{~mm}$ sucrose, $1 \mathrm{~mm}$ PMSF, 1 $\mu \mathrm{g} / \mathrm{ml}$ leupeptin, $4 \mathrm{~mm}$ benzamidine, $1 \mu \mathrm{g} / \mathrm{ml}$ pepstatin A, and $2 \mu \mathrm{g} / \mathrm{ml}$ aprotinin in PBS. Samples were then further homogenized by repeated trituration through a small-gauge needle and then aliquoted and stored at $-80^{\circ} \mathrm{C}$ until needed. Proteins were separated by SDS-PAGE. SDS-PAGE was done with 12 or $4-20 \%$ gradient Tris-glycine precast gels (Invitrogen, San Diego, CA), and separated proteins were then transferred onto polyvinylidene difluoride membranes. The membranes were blocked for $1 \mathrm{hr}$ using 5\% powdered milk in PBS-0.2\% Tween 20 and then incubated overnight at $4^{\circ}$ in $1 \mu \mathrm{g} / \mathrm{ml}$ rabbit anti-Kir4.1 generated against the peptide CEKEGSALSVRISNV. The blots were washed in blocking solution three times for $15 \mathrm{~min}$ each and then exposed to HRPconjugated goat anti-rabbit secondary antibody for $1 \mathrm{hr}$ at room temperature. Blots were washed three times for 15 min each in PBS-0.2\% Tween 20 and then two times for 10 min each in PBS. Immunoreactive bands were visualized using Lumi-Light Plus (Roche Products, Hertforshire, UK) onto Hyperfilm ECL chemiluminescence film (Amersham Biosciences, Little Chalfont, UK).

\section{RESULTS}

\section{Dp71 is involved in Kir4.1 localization}

Based on the similar subcellular distribution of Kir4.1 (Kof uji et al., 2000) and Dp71 (Howard et al., 1998) in Müller cells, we sought to identify a role for Dp71 in the localization of Kir4.1 in mouse retinas. We used $\mathrm{mdx}^{3 C v}$ mice, which lack all functional dystrophin isoforms (see Fig. $3 A$ ), to immunolocalize Kir4.1 in the absence of functional Dp71. Figure $1, A$ and $B$, shows the distribution of Kir4.1 immunostaining in wild-type and $\mathrm{mdx}^{3 C v}$ retinal sections, respectively. The distribution of Kir4.1 immunostaining in the wild-type mouse (Fig. 1 $A$ ) with its prominent concentration at the inner limiting membrane (arrow) and around capillaries (arrowheads) in the retina is in agreement with previous studies (Ishii et al., 1997; Kofuji et al., 2000). Furthermore, double labeling with anti-glutamine synthetase (Fig. 1C) shows considerable immunoreactivity overlap in the inner limiting membrane (Fig. 1E), as expected for the expression of Kir4.1 channels in Müller cells. This pattern of immunolocalization of Kir4.1 in retina was taken previously to indicate the highly clustered expression of Kir4.1 channels in the endfoot and perivascular processes of Müller cells. Immunoelectron microscopy studies (Nagelhus et al., 1999) and the staining of enzymatically dissociated cells (results not shown) confirmed that Kir4.1 in retina is restricted to Müller cells and highly regionalized in these cells.

Using the same anti-Kir4.1 antibody in retinas from $\mathrm{mdx}^{3 C v}$ mouse (Fig. $1 B$ ), the localization pattern was strikingly different. Kir4.1 immunoreactivity is apparent in many areas of the retina from the inner limiting membrane to the outer limiting membrane. The dense network of fine processes in the inner plexiform layer (IPL) and outer plexiform layer (OPL) and the staining of cell bodies in the inner nuclear layer and the outer limiting membrane all indicate that Müller cells were labeled. Indeed, considerable double labeling of glutamine synthetase and Kir4.1 is seen in these sections (Fig. $1 F$ ). Compared with the retina from the wild-type mouse, the inner limiting membrane of the mutant 


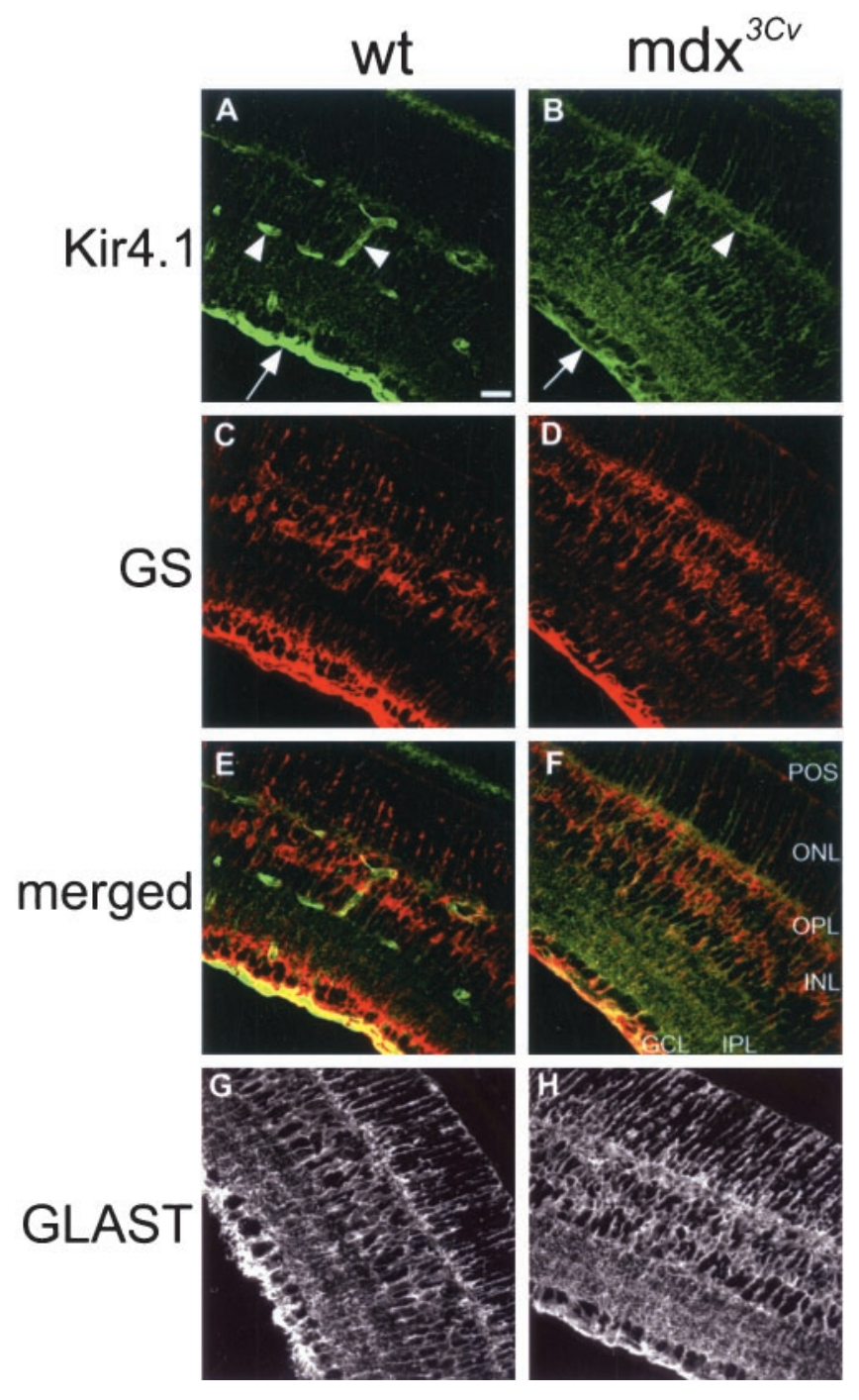

Figure 1. Kir4.1 localization in wild-type $(w t)$ and $\mathrm{mdx}^{3 C v}$ retinal sections. A, Kir4.1 is concentrated at the inner limiting membrane (arrow) and to processes around blood vessels in wild-type retina (arrowheads). B, In the $\mathrm{mdx}^{3 C v}$ mouse, Kir4.1 appeared to be evenly distributed throughout the retina, and there appeared to be a reduction in staining at the inner limiting membrane (arrow) and no apparent enrichment of Kir4.1 around blood vessels (arrowheads). The Müller-specific marker glutamine synthetase $(G S ; C, D)$ and merged images (merged; $E, F)$ suggest the localization of Kir4.1 to Müller cells. POS, Photoreceptor outer segments; $O N L$, outer nuclear layer; $I N L$, inner nuclear layer. $G, H$, Retinal sections from wild type and $\mathrm{mdx}^{3 C v}$ were stained for GLAST. The structural integrity of Müller cells and their fine processes in the mutant mouse appeared to be intact and indistinguishable from that of the wild type. Scale bar, $25 \mu \mathrm{m}$.

mouse (Fig. 1B, arrow) displays only a slightly higher intensity of Kir4.1 staining compared with other regions of the Müller cells, whereas processes lining blood vessels (Fig. 1B, arrowheads) do not display any apparent increase in staining intensity. The overall staining for Kir4.1 was significantly reduced in the $\mathrm{mdx}^{3 \mathrm{C} v}$ mouse (data not shown) so, for adequate presentation of the distribution of Kir4.1, the excitation intensity of the confocal microscope was increased.

Some sections from wild-type and $\mathrm{mdx}^{3 C v}$ mice were immunostained for GLAST, which is highly enriched in Müller cell membranes (Derouiche and Rauen, 1995; Lehre et al., 1997). Staining for GLAST (Fig. $1 G, H$ ) revealed no noticeable differ-
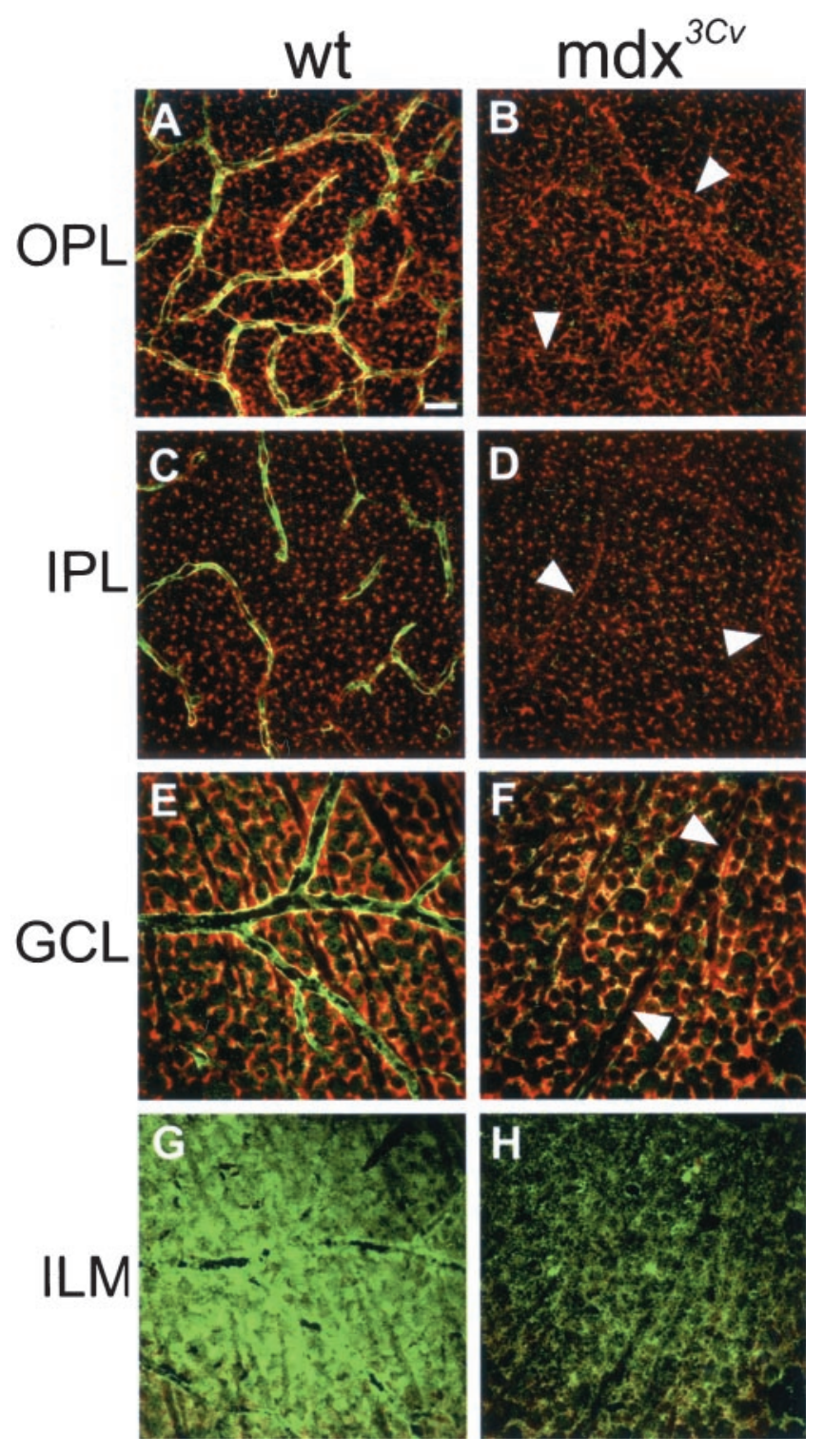

Figure 2. Kir4.1 localization in wild-type $(w t)$ and $\mathrm{mdx}^{3 C v}$ whole-mount retinal tissue. In both mice, optical sections were taken from the OPL $(A$, $B)$, the IPL $(C, D)$, the GCL $(E, F)$, and the inner limiting membrane $(I L M ; D, H)$. In the wild-type mouse $(A, C, E, G), \operatorname{Kir} 4.1$ was prominently detected in processes surrounding blood vessels (green) in the OPL, IPL, and GCL, respectively, whereas glutamine synthetase staining (red) revealed the location of Müller cells. Colocalization is indicated by yellow areas. Kir4.1 staining is prominently displayed at the inner limiting membrane of the wild type $(G)$. Arrowheads $(B, D, F)$ delineate blood vessels present in the OPL, IPL, and GCL, respectively, of the $\mathrm{mdx}^{3 C v}$ mouse that were not noticeably stained for Kir4.1. Uneven staining intensity in $G$ and $H$ resulted from the retina not being completely flat. Scale bar, $25 \mu \mathrm{m}$.

ences in immunoreactivity between Müller cells from wild-type and $\mathrm{mdx}^{3 C v}$ mice, with strong labeling of the inner limiting membrane, cell body, proximal and distal stalks, and outer limiting membrane. Therefore, the reduction of Kir4.1 staining in foot processes of $\mathrm{mdx}^{3 C v}$ mice does not appear to be attributable to global alterations in the structure of Müller cells in the mutant mouse.

Whole-mount immunocytochemistry was also conducted, examining four layers: the OPL (Fig. $2 A, B$ ), IPL (Fig. $2 C, D$ ), 

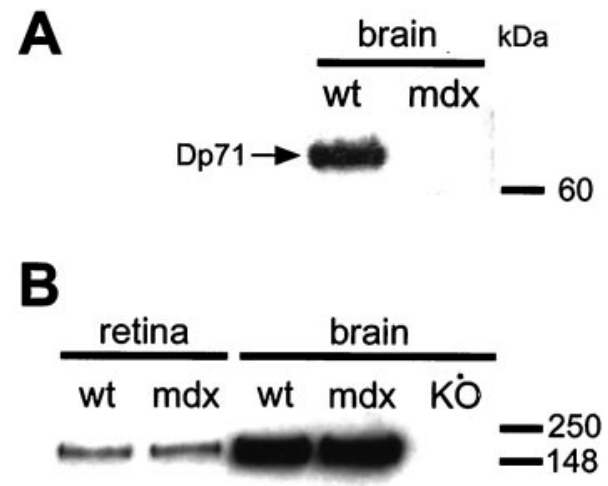

$-60$

Figure 3. A, A Western blot was performed using brain lysates from wild-type (wt) and $\mathrm{mdx}^{3 C v}$ mice and was exposed to an antibody specific for the hydrophobic $\mathrm{C}$ terminus of dystrophin. The lack of immunodetection in the $\mathrm{mdx}^{3 \mathrm{Cv}}$ lane confirms a lack of Dp71 in the mutant mouse. $B$, A Western blot showing expression levels of Kir4.1 in wild-type versus $\mathrm{mdx}^{3 C v}$ brain and retina. A band at $\sim 200 \mathrm{kDa}$ represents Kir4.1 in its tetrameric form. Brain tissue from the Kir4.1 knock-out (KO) mouse was used as a negative control ( far right lane). There was no distinguishable difference in Kir4.1 expression between wild-type and $\mathrm{mdx}^{3 C v}$ mouse.

ganglion cell layer (GCL) (Fig. 2E,F), and the inner limiting membrane (Fig. 2G,H). As expected, the whole-mount tissue revealed an enrichment of Kir4.1 immunoreactivity around the blood vessels and along the inner limiting membrane in the wild-type mouse. The $\mathrm{mdx}^{3 C v}$ mouse revealed a markedly different staining pattern. Arrowheads in Figure 2, B, D, and F, delineate blood vessels in the OPL, IPL, and GCL, respectively, in the mutant mouse that were not detected by staining with anti-Kir4.1. Overall, Kir4.1 staining is barely detectable in all areas examined, except for at the GCL, in which processes from Müller cells interspersed between ganglion cell bodies display marked Kir4.1 immunoreactivity (Fig. 2E,F).

We conclude that Kir4.1 is expressed in $\mathrm{mdx}^{3 C v}$ mouse Müller cells with a strikingly different subcellular localization than in wild type. Although Kir4.1 channels are expressed in a highly non-uniform manner in wild-type Müller cells, they are expressed homogeneously in the plasma membrane in $\mathrm{mdx}^{3 C v}$ mouse.

\section{Loss of Dp71 does not affect the expression of Kir4.1}

To address the question whether the overall expression of Kir4.1 channels is reduced in $\mathrm{mdx}^{3 C v}$ mice, Western blots were performed to compare the expression level of Kir4.1 in wild-type and $\mathrm{mdx}^{3 C v}$ mice. Whole-brain and retinal extracts from both mice were subjected to SDS-PAGE, and anti-Kir4.1 antibody was used on immunoblots. The anti-Kir4.1 antibody detected one distinct band of apparent molecular mass of $200 \mathrm{kDa}$ (Fig. 3B) in brain and retina protein extracts. The molecular mass of Kir4.1 polypeptide predicted from analysis of its amino acid sequence is $42 \mathrm{kDa}$; thus, the low electrophoretic mobility of Kir4.1 most likely reflects our failure to disaggregate the tetrameric Kir4.1 channel complexes. Similar low electrophoretic mobility for Kir4.1 in Western blots has been described previously using other anti-Kir4.1 antibodies (Li et al., 2001). As expected, this band was not detected in brain tissue of a Kir4.1 knock-out mouse, even at long exposure times. Comparison of the expression levels for Kir4.1 between the wild-type and $\mathrm{mdx}^{3 C v}$ mouse did not reveal obvious differences in brain or retina. These results indicate that, despite the distinct expression pattern of Kir4.1 in $\mathrm{mdx}^{3 C v}$ retina, its expression level is similar to wild-type retina.

\section{Loss of Dp71 does not affect Müller cell Kir currents}

Considering that Dp71 is a major component of the membraneassociated DAPC in Müller cells (Claudepierre et al., 2000), it is possible that lack of functional Dp71 could affect the trafficking to and possible insertion of Kir4.1 to the cell membrane. To address this issue, we examined the functional expression of Kir currents in isolated Müller cells from the wild-type and $\mathrm{mdx}^{3 C v}$ mouse. Kir4.1 is the predominant potassium conductance in mouse Müller cells (Kof uji et al., 2000), so evoked $\mathrm{K}^{+}$currents in these cells are primarily reflective of Kir4.1 activity. Single isolated Müller cells from wild-type and $\mathrm{mdx}^{3 C v}$ mice were voltage clamped to $-80 \mathrm{mV}$, and voltage steps of $400 \mathrm{msec}$ were applied from -140 to $+50 \mathrm{mV}$ in $10 \mathrm{mV}$ increments. Trials were conducted with the use of an extracellular solution consisting of 2.5 $\mathrm{mM} \mathrm{K}^{+}$with or without the addition of either $100 \mu \mathrm{M}$ or $1 \mathrm{~mm}$ $\mathrm{BaCl}_{2}$.

Figure 4 shows representative traces in wild-type and $\mathrm{mdx}^{3 C v}$ Müller cells. In Müller cells from both mice, large timeindependent inward currents and outward currents with both a transient and sustained component were detected. The overall profile of the recorded currents is in close agreement to those described previously in Müller cells from rat (Felmy et al., 2001), rabbit (Francke et al., 2001), and humans (Bringmann et al., 1999). Current-voltage ( $I-V$ ) relationships were constructed using current values measured at $392 \mathrm{msec}$ after initiation of the voltage step. All of the $I-V$ curves reversed at approximately -90 $\mathrm{mV}$, which falls close to the calculated Nernst potential for $\mathrm{K}^{+}$of $-97 \mathrm{mV}$ based on our pipette and bath solutions. Moreover, both the inward and outward currents were attenuated as the extracellular concentration of $\mathrm{BaCl}_{2}$ was raised. These data support the notion that the inward currents measured under these experimental conditions are carried by $\mathrm{K}^{+}$ions through Kir channels. As seen in Figure $4 C-E$, the membrane potential as well as the current and current density at $-120 \mathrm{mV}$ in Müller cells from wild-type and mutant mice are similar. Together, these data show that Kir channels are expressed at the cell membrane in $\mathrm{mdx}^{3 \mathrm{Cv}}$ Müller cells at normal levels, despite their mislocalization and apparent failure to interact with the DAPC.

\section{Physiological determination of potassium conductance mislocalization}

Measurements of membrane potential in Müller cells during focal increases in $\left[\mathrm{K}^{+}\right]_{\mathrm{o}}$ concentration have been used to assess the regional $\mathrm{K}^{+}$conductance (Newman, 1987). Such regional conductance is dependent on the specific conductance to $\mathrm{K}^{+}$times the total surface of the cell exposed to the high $\left[\mathrm{K}^{+}\right]_{\mathrm{o}}$. In vascularized retinas, such as in mouse, there is considerable nonuniform distribution of $\mathrm{K}^{+}$conductance in the Müller cell (Newman, 1987). The regions with the highest conductance were the endfoot and in middle portion of the cells, which is hypothesized to reflect the high density of Kir channels in the endfoot and perivascular processes of the Müller cells (Newman, 1987).

If indeed the Kir4.1 channels in $\operatorname{mdx}^{3 C v}$ Müller cells were uniformly distributed, then lesser variations in the regional $\mathrm{K}^{+}$ conductance in these cells compared with wild-type cells would be expected. To examine the regional $\mathrm{K}^{+}$conductance in $\mathrm{mdx}^{3 \mathrm{Cv}}$ and wild-type Müller cells, cells were voltage clamped to -80 $\mathrm{mV}$, high $\left[\mathrm{K}^{+}\right]$solution was focally applied to selected regions of 
A
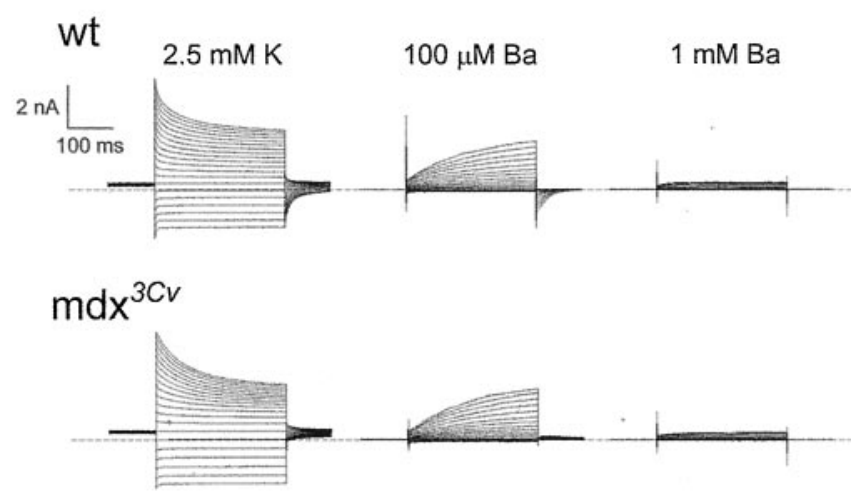

B

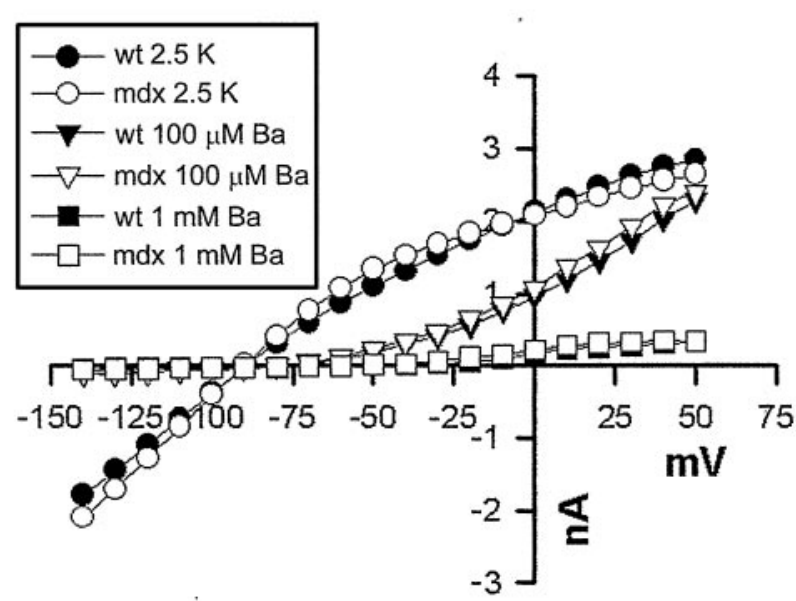

C

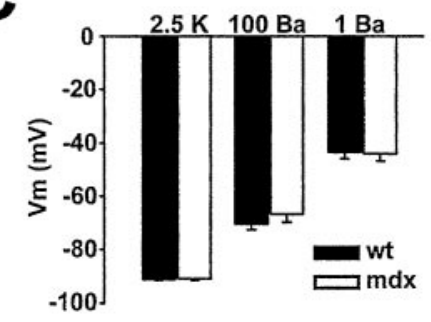

D

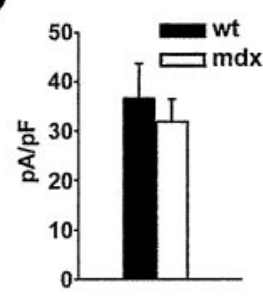

$\mathbf{E}$

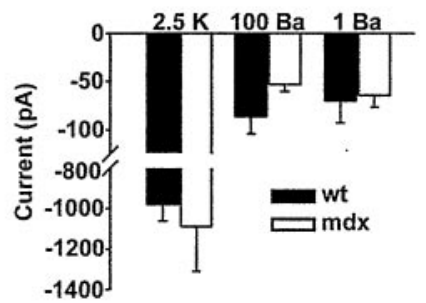

Figure 4. Müller cell whole-cell electrophysiology in wild-type $(w t)$ and mdx $^{3 C v}$ mouse. $A$, Representative traces from Müller cells recorded in extracellular solutions containing no $\mathrm{BaCl}_{2}$ (left), $100 \mu \mathrm{M} \mathrm{BaCl}_{2}$ (middle), and $1 \mathrm{mM} \mathrm{BaCl}_{2}$ (right). $B$, Current-voltage relationships of the recordings in $A$. $C$, Resting membrane potential $\left(V_{\mathrm{m}}\right)$ was measured in wild-type (black bars) and $\mathrm{mdx}^{3 C v}$ (white bars) dissociated Müller cells in normal extracellular solution $(2.5 K)$ and in the same solution with the addition of $100 \mu \mathrm{M} \mathrm{BaCl}_{2}(100 \mathrm{Ba})$ or $1 \mathrm{mM} \mathrm{BaCl} \mathrm{Ba}_{2}(1 \mathrm{Ba})$. D, Current density was the cells, and evoked currents were recorded. Such currents were recorded from eight distinct regions of Müller cells, ranging from the endfoot to the apical end. Figure $5 A$ shows representative currents evoked from their respective regions in a wild-type and $\mathrm{mdx}^{3 C v}$ Müller cell. In general, the current profile in wild-type cells consistently showed large currents at the endfoot and then a reduction in current in the proximal process, followed by a considerable increase in current in the somatic and apical regions (Fig. 5A). In $\mathrm{mdx}^{3 C v}$ Müller cells, however, the current was consistently weakest in the endfeet, with a gradual increase moving up the proximal process, followed by a large increase in the somatic and apical regions. The relative current response in each region was normalized to the response obtained in the endfoot (Fig. $5 B)$, whereby a significant difference $(p>0.05)$ between the wild-type and $\mathrm{mdx}^{3 C v}$ mice in the two measured regions in the proximal process adjacent to the endfoot was seen. This current profile alteration in $\mathrm{mdx}^{3 C v}$ Müller cells is consistent with the expected current profile in cells in which Kir4.1 is mislocalized, as seen in our immunocytochemical studies (Figs. 1, 2).

\section{DISCUSSION}

This study is the first to demonstrate the critical role of a dystrophin isoform for the targeting and subcellular distribution of a potassium channel in glial cells. Our immunocytochemical and electrophysiological results demonstrate that functional expression of the dystrophin isoform Dp71 is necessary for the highly asymmetric expression of the inwardly rectifying potassium channel Kir4.1 in the main glial cell type in retina, the Müller cells.

Genetic inactivation of the weakly inwardly rectifying potassium channel Kir4.1 in mice demonstrated that this particular Kir subunit sets the membrane potential in Müller cells and underlies the main potassium conductance in these cells (Kofuji et al., 2000). Such marked asymmetric and clustered distribution of Kir4.1 subunits in these specialized glial cells has presumably the important physiological function of promoting the efficient buffering of extracellular potassium concentration in the retina (Newman et al., 1984). Although the cellular localization of Kir4.1 channels in other tissues is still a matter of controversy, recent findings suggest a similar clustered distribution of Kir4.1 channels in the astrocyte endfeet adjacent to blood vessels in brain (Higashi et al., 2001). Thus, the clustered and polarized distribution of Kir4.1 channels may play a analogous role in astrocytes in brain as that of Müller cells in retina. Relevant to our findings, Dp71 is also expressed in astrocytes in brain (Aleman et al., 2001). Marked neurological dysfunctions for the mouse line $\mathrm{mdx}^{3 C v}$ has not been reported, but it is likely that a perturbation in the potassium buffering function in brain would only manifest under conditions of high neuronal activity.

In our immunohistochemistry experiments, Kir4.1 distribution in the Müller cells from $\mathrm{mdx}^{3 C v}$ mouse not only appeared to be

\section{$\leftarrow$}

calculated by first subtracting the evoked current at $-120 \mathrm{mV}$ with blockade by $1 \mathrm{mM} \mathrm{BaCl}_{2}$ from the evoked current at $-120 \mathrm{mV}$ with $2.5 \mathrm{~K}$ extracellular solution in each cell. This value was then divided by membrane capacitance measured under blockade by $1 \mathrm{mM} \mathrm{BaCl}_{2}$. $(\mathrm{Membrane}$ capacitance was recorded under barium blockade based on the increased ability to obtain a more accurate exponential fit under such high membrane resistance.) $E$, Currents at $-120 \mathrm{mV}$ were recorded in whole-cell clamp mode with a $400 \mathrm{msec}$ pulse of $-120 \mathrm{mV}$ from a holding potential of $-80 \mathrm{mV}$. The data point was taken $392 \mathrm{msec}$ from the start of the voltage step. $x$-Axis labeling as in $C$. There were no significant current differences in wild type versus $\mathrm{mdx}^{3 C v}$ in $C-E$. 
A

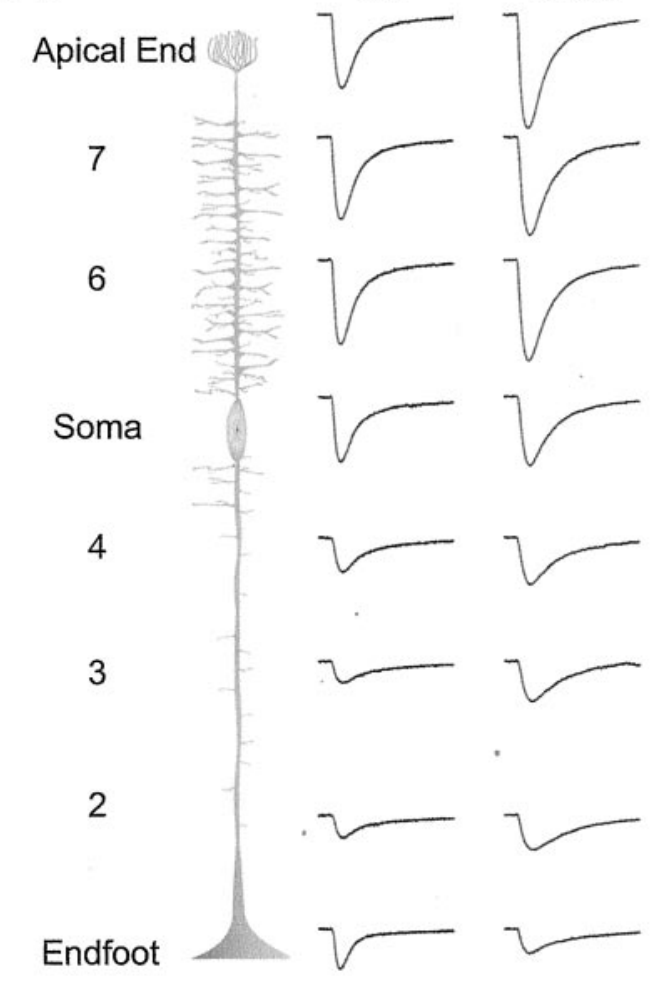

B

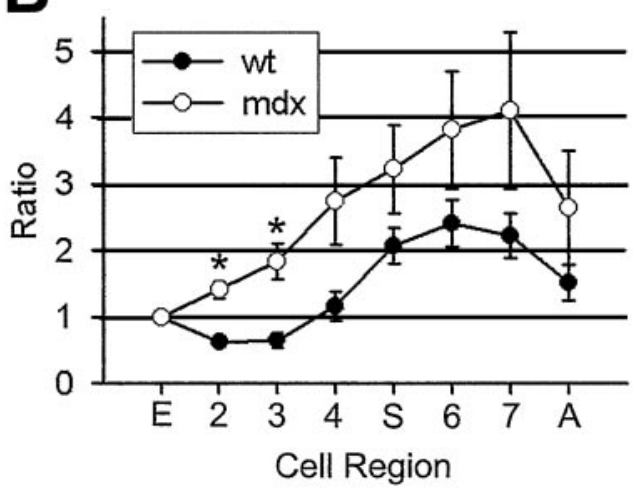

Figure 5. Regional $\mathrm{K}^{+}$conductance is affected in $\mathrm{mdx}^{3 C v}$ Müller cells. $A$, Representative traces from whole-cell clamped Müller cells to which focal ejections of a $50 \mathrm{~mm} \mathrm{~K}^{+}$solution were applied. The Müller cell diagram on the left is oriented such that the apical end is at the top and the endfoot is at the bottom, and the left and right columns show $\mathrm{K}^{+}$-evoked depolarization traces from wild-type and $\mathrm{mdx}^{3 C v}$ mice, respectively. Note the differences between cells with respect to current amplitudes in the endfoot and proximal stalk (regions 2,3, and 4). B, Peak currents in each cell region were normalized to their respective peak endfoot current, and these values for all cells in each condition were averaged and plotted. The wild-type cells ( filled circles; $n=9$ ) maintained smaller normalized conductances in regions $2(0.62 \pm 0.20)$ and $3(0.65 \pm 0.31)$ in the proximal stalk, whereas the $\operatorname{mdx}^{3 C v}$ mouse (open circles; $n=8$ ) demonstrated a larger normalized conductance in regions $2(1.41 \pm 0.36)$ and 3 $(1.84 \pm 0.74) .{ }^{*} p<.05$.

mislocalized, but there also appeared to be an overall reduction in staining intensity. The impression that the channel number is reduced in the $\mathrm{mdx}^{3 C v}$ Müller cells by immunocytochemistry may be caused by the redistribution of Kir4.1 immunoreactivity in these cells rather than a reduction of plasma membrane expres- sion of Kir4.1 channels. Indeed, Western blots and electrophysiological experiments show overall similar channel expression in Müller cells from the wild-type and mutant mouse.

The potassium ejection experiments revealed a significant difference in Kir currents in the endfeet and proximal stalk regions of Müller cells in the $\mathrm{mdx}^{3 C v}$ mouse, as expected from the redistribution of Kir4.1. However, the redistribution did not appear to be complete, because the currents in the somatic and apical regions of the cells were considerably larger than the endfoot and stalk. Despite the polarized localization pattern of Kir4.1 in Müller cells as revealed by immunocytochemistry (Ishii et al., 1997; Kofuji et al., 2000), actual Kir currents from Müller cells in organisms with vascularized retinas are characteristically distributed such that the majority of the current lies in the somatic and apical regions (Newman, 1987). This may be attributable to an enrichment of fine membranous processes resulting in a net majority of channels in these areas or may be attributable to the contribution of other Kir currents in Müller glial cells (P. Kofuji, unpublished observations).

Although the exact molecular mechanism for the dependency of the dystrophin isoform Dp71 for the concentration and localization of Kir4.1 in the Müller cells membranes is not known, there is evidence to suggest the participation of a dystrophinassociated protein in these functions. First, Kir4.1 primarily colocalizes with AQP4 in Müller cells (Nagelhus et al., 1999). Both Kir4.1 and AQP4 contain the C-terminal consensus motif for the binding to modular domains on interacting proteins known as PDZ domains (Doyle et al., 1996), suggesting a common mechanism for localization. Second, evidence has accumulated suggesting the involvement of the DAPC in the localization of ion channels, receptors, and signaling molecules via interactions with the PDZ domain-containing protein $\alpha$-syntrophin (Brenman et al., 1996). In vivo, $\alpha$-syntrophin can form a PDZmediated stable complex with AQP4 in muscle and brain (Adams et al., 2001; Neely et al., 2001), whereas, in vitro, syntrophin PDZ domains can bind the voltage-gated potassium channel Kv1.4 and C-terminal peptides from NMDA receptor subunit NR2B (Gee et al., 1998). Our results would suggest that intermolecular associations between $\alpha$-syntrophin or another PDZ domaincontaining protein is relevant for the clustered and polarized distribution of Kir4.1 in Müller cells but not for its expression on the membrane surface. Indeed, the expression levels of the barium-sensitive inward currents were identical in the Müller cells from wild-type and $\mathrm{mdx}^{3 C v}$ mice.

Muscular dystrophy patients (Cibis et al., 1993; Pillers et al., 1993; Fitzgerald et al., 1994; Sigesmund et al., 1994), $\mathrm{mdx}^{3 C v}$ mice (Pillers et al., 1995), and AQP4 null mutant mice (Li et al., 2002) display abnormalities in electroretinogram recordings, particularly a reduction in b-wave amplitude. Although there has been considerable controversy around the origin of the b-wave, there has been some support for a Müller cell origin (Miller and Dowling, 1970; Kline et al., 1978; Newman and Odette, 1984; Wen and Oakley, 1990). Thus, the intriguing possibility is that the distribution of Kir4.1 channels and AQP4 in Müller cells is dependent on the tethering of these molecules to the large DAPC to form a linked water and potassium conductance unit and that the highly asymmetric distribution of Kir4.1 channels and AQP4 is important for Müller cell and retinal physiology. Additional biochemical experiments will be necessary to address such a possibility. 


\section{REFERENCES}

Adams ME, Mueller HA, Froehner SC (2001) In vivo requirement of the alpha-syntrophin PDZ domain for the sarcolemmal localization of nNOS and aquaporin-4. J Cell Biol 155:113-122.

Aleman V, Osorio B, Chavez O, Rendon A, Mornet D, Martinez D (2001) Subcellular localization of Dp71 dystrophin isoforms in cultured hippocampal neurons and forebrain astrocytes. Histochem Cell Biol 115:243-254.

Brenman JE, Chao DS, Gee SH, McGee AW, Craven SE, Santillano DR, WuZ, Huang F, Xia H, Peters MF, Froehner SC, Bredt DS (1996) Interaction of nitric oxide synthase with the postsynaptic density protein PSD-95 and alpha1-syntrophin mediated by PDZ domains. Cell 84:757-767.

Bringmann A, Francke M, Pannicke T, Biedermann B, Faude F, Enzmann V, Wiedemann P, Reichelt W, Reichenbach A (1999) Human Müller glial cells: altered potassium channel activity in proliferative vitreoretinopathy. Invest Ophthalmol Vis Sci 40:3316-3323.

Cibis GW, Fitzgerald KM, Harris DJ, Rothberg PG, Rupani M (1993) The effects of dystrophin gene mutations on the ERG in mice and humans. Invest Ophthalmol Vis Sci 34:3646-3652.

Claudepierre T, Dalloz C, Mornet D, Matsumura K, Sahel J, Rendon A (2000) Characterization of the intermolecular associations of the dystrophin-associated glycoprotein complex in retinal Müller glial cells. J Cell Sci 113:3409-3417.

Cox GA, Phelps SF, Chapman VM, Chamberlain JS (1993) New mdx mutation disrupts expression of muscle and nonmuscle isoforms of dystrophin. Nat Genet 4:87-93.

Derouiche A, Rauen T (1995) Coincidence of L-glutamate/L-aspartate transporter (GLAST) and glutamine synthetase (GS) immunoreactions in retinal glia: evidence for coupling of GLAST and GS in transmitter clearance. J Neurosci Res 42:131-143.

Doyle DA, Lee A, Lewis J, Kim E, Sheng M, MacKinnon R (1996) Crystal structures of a complexed and peptide-free membrane proteinbinding domain: molecular basis of peptide recognition by PDZ. Cell 85:1067-1076.

Felmy F, Pannicke T, Richt JA, Reichenbach A, Guenther E (2001) Electrophysiological properties of rat retinal Müller (glial) cells in postnatally developing and in pathologically altered retinae. Glia 34:190-199.

Fitzgerald KM, Cibis GW, Giambrone SA, Harris DJ (1994) Retinal signal transmission in Duchenne muscular dystrophy: evidence for dysfunction in the photoreceptor/depolarizing bipolar cell pathway. J Clin Invest 93:2425-2430.

Francke M, Faude F, Pannicke T, Bringmann A, Eckstein P, Reichelt W, Wiedemann P, Reichenbach A (2001) Electrophysiology of rabbit Müller (glial) cells in experimental retinal detachment and PVR. Invest Ophthalmol Vis Sci 42:1072-1079.

Gee SH, Madhavan R, Levinson SR, Caldwell JH, Sealock R, Froehner SC (1998) Interaction of muscle and brain sodium channels with multiple members of the syntrophin family of dystrophin-associated proteins. J Neurosci 18:128-137.

Hamill OP, Marty A, Neher E, Sakmann B, Sigworth FJ (1981) Improved patch-clamp techniques for high-resolution current recording from cells and cell-free membrane patches. Pflügers Arch 391:85-100.

Higashi K, Fujita A, Inanobe A, Tanemoto M, Doi K, Kubo T, Kurachi Y (2001) An inwardly rectifying $\mathrm{K}(+)$ channel, Kir4.1, expressed in astrocytes surrounds synapses and blood vessels in brain Am J Physiol Cell Physiol 281:C922-931.

Howard PL, Dally GY, Wong MH, Ho A, Weleber RG, Pillers DA, Ray PN (1998) Localization of dystrophin isoform Dp71 to the inner limiting membrane of the retina suggests a unique functional contribution of Dp71 in the retina. Hum Mol Genet 7:1385-1391.
Ishii M, Horio Y, Tada Y, Hibino $\mathrm{H}$, Inanobe A, Ito M, Yamada M, Gotow T, Uchiyama Y, Kurachi Y (1997) Expression and clustered distribution of an inwardly rectifying potassium channel, KAB-2/ Kir4.1, on mammalian retinal Müller cell membrane: their regulation by insulin and laminin signals. J Neurosci 20:7725-7735.

Kline RP, Ripps H, Dowling JE (1978) Generation of b-wave currents in the skate retina. Proc Natl Acad Sci USA 75:5727-5731.

Kofuji P, Ceelen P, Zahs KR, Surbeck LW, Lester HA, Newman EA (2000) Genetic inactivation of an inwardly rectifying potassium channel (Kir4.1 subunit) in mice: phenotypic impact in retina. J Neurosci $20.5733-5740$.

Lehre KP, Davanger S, Danbolt NC (1997) Localization of the glutamate transporter protein GLAST in rat retina. Brain Res 744:129-137.

Li J, Patil RV, Verkman AS (2002) Mildly abnormal retinal function in transgenic mice without Muller cell aquaporin-4 water channels. Invest Ophthalmol Vis Sci 43:573-579.

Li L, Head V, Timpe LC (2001) Identification of an inward rectifier potassium channel gene expressed in mouse cortical astrocytes. Glia 33:57-71.

Miller RF, Dowling JE (1970) Intracellular responses of the Muller (glial) cells of mudpuppy retina: their relation to b-wave of the electroretinogram. J Neurophysiol 33:323-341.

Nagelhus E, Horio Y, Inanobe A, Fujita A, Haug F, Nielsen S, Kurachi Y, Ottersen O (1999) Immnunogold evidence suggests that coupling of $\mathrm{K}^{+}$siphoning and water transport in rat retinal Müller cells is mediated by coenrichment of Kir4.1 and AQP4 in specific membrane domains. Glia 26:47-54

Neely JD, Amiry-Moghaddam M, Ottersen OP, Froehner SC, Agre P, Adams ME (2001) Syntrophin-dependent expression and localization of Aquaporin-4 water channel protein. Proc Natl Acad Sci USA 98:14108-14113

Newman E (1985) Membrane physiology of retinal glial (Müller) cells. J Neurosci 5:2225-2239.

Newman E (1987) Distribution of potassium conductance in mammalian Müller (glial) cells: a comparative study. J Neurosci 7:2423-2432.

Newman E (1993) Inward-rectifying potassium channels in retinal glial (Müller) cells. J Neurosci 13:3333-3345.

Newman EA, Odette LL (1984)Model of electroretinogram b-wave generation: a test of the $\mathrm{K}^{+}$hypothesis. J Neurophysiol 51:164-182.

Newman EA, Frambach DA, Odette LL (1984) Control of extracellular potassium levels by retinal glial cell $\mathrm{K}^{+}$siphoning. Science 225:11741175.

Pillers DM, Bulman DE, Weleber RG, Sigesmund DA, Musarella MA, Powell BR, Murphey WH, Westall C, Panton C, Becker LE, Worton RG, Ray PN (1993) Dystrophin expression in the human retina is required for normal function as defined by electroretinography. Nat Genet 4:82-86.

Pillers DM, Weleber RG, Woodward WR, Green DG, Chapman VM, Ray PN (1995) mdxCv3 mouse is a model for electroretinography of Duchenne/Becker muscular dystrophy. Invest Ophthalmol Vis Sci $36: 462-466$

Sheng M, Kim E (1996) Ion channel associated proteins. Curr Opin Neurobiol 6:602-608.

Sheng M, Wyszynsky M (1997) Ion channel targeting in neurons. BioEssays 19:847-853.

Sigesmund DA, Weleber RG, Pillers DA, Westall CA, Panton CM, Powell BR, Heon E, Murphey WH, Musarella MA, Ray PN (1994) Characterization of the ocular phenotype of Duchenne and Becker muscular dystrophy. Ophthalmology 101:856-865.

Wen R, Oakley B (1990) K(+)-evoked Muller cell depolarization generates b-wave of electroretinogram in toad retina. Proc Natl Acad Sci USA 87:2117-2121. 